\title{
Detection of phenol by incorporation of gold modified-enzyme based graphene oxide thin film with surface plasmon resonance technique
}

\begin{abstract}
The usage of porcine pepsin or other porcine derivatives in food products is a common practice in European, American and certain Asian countries although it creates issues in religious and personnel health concerns. In this study, porcine pepsin was detected using indirect ELISA that involved the anti-pep80510 polyclonal antibody raised against a specific peptide of porcine pepsin, pep80510. The sensitivity of the assay for standard porcine pepsin was $0.008 \mu \mathrm{g} / \mathrm{g}$. The immunoassay did not cross-react to other animal rennet and milk proteins except for microbial coagulant from Mucor miehie. The recovery of porcine pepsin in spiked cheese curd within the range of $\mathrm{CV}<20 \%$ while for porcine pepsin in spiked cheese whey the recovery is also within the range of $\mathrm{CV} \%<20 \%$.
\end{abstract}

Keyword: Peptide; Polyclonal antibody; ELISA; Porcine pepsin; Cheese 